\title{
Posterior Surface of the Liver
}

National Cancer Institute

\section{Source}

National Cancer Institute. Posterior Surface of the Liver. NCI Thesaurus. Code C33380.

The posterior aspect of the liver. 